\title{
Calendar of Events (from October 2021 - December 2021)
}

\section{October 2021}

- EANS 2021

October 3-7, Hamburg, Germany (Virtual meeting)

https://eanscongress.org

- 2021 CNS Annual Meeting

October 16-20, Austin, Texas, USA

https://2021meeting.cns.org/

- SMISS 21 Annual Forum

October 28-30, Las Vegas, NV USA

https://smiss.memberclicks.net

\section{November 2021}

- Global Spine Congress 2021

November 3-6, Paris, France (Hybrid meeting)

http://gsc2021.org

- 3rd International conference of NESON 3rd International Conference of NESON (INCONESON III), 2nd Interim Meeting of AASNS \& 2nd Annual meeting of Spine Chapter of NESON

November 26-28, Kathmandu, Nepal (Hybrid meeting)

http://neson.org

\section{December 2021}

- 69th Annual Conference of Neurological Society of India

December 10-12 (Virtual meeting)

https://neurosocietyindia.org

Note: Due to the Global Pandemic of COVID-19, it is advisable to postpone any travel for now and check Travel Advisories before planning. For academic enrichment one can attend online webinars or use resources provided by various societies like AANS, CNS, EANS, AO Spine, NASS to name a few.

\section{Important e-learning Neurosurgery sites:}

- Congress of Neurological Surgeons: Complimentary online education https://www.cns.org/onlineed

- American Association of Neurological Surgeons: Online education https://education.aans.org/online-education

- American Spinal Injury Association https://asia-spinalinjury.org/asia-sci-webinars/

- World Federation of Neurosurgical Societies Spine Committee http://wfns-spine.org

DOI: https://doi.org/10.3126/njn.v18i3.39337 